\title{
(C) OPEN ACCESS \\ Cigarette pack messages about toxic chemicals: a randomised clinical trial
}

\author{
Noel T Brewer, ${ }^{1,2}$ Michelle Jeong, ${ }^{1,2}$ Jennifer R Mendel, ${ }^{1}$ Marissa G Hall, ${ }^{1,2}$ \\ Dongyu Zhang, ${ }^{3}$ Humberto Parada $\mathrm{Jr}^{4}{ }^{4}$ Marcella $\mathrm{H}$ Boynton, ${ }^{1,2}$ Seth M Noar ${ }^{2,5}$ \\ Sabeeh A Baig, ${ }^{1}$ Jennifer C Morgan, Kurt M Ribis| ${ }^{1,2}$
}

\begin{abstract}
- Additional material is published online only. To view please visit the journal online (http://dx.doi.org/10.1136/ tobaccocontrol-2017-054112).
\end{abstract}

${ }^{1}$ Department of Health Behavior, Gillings School of Global Public Health, University of North Carolina, Chapel Hill, North Carolina, USA

${ }^{2}$ Lineberger Comprehensive Cancer Center, University of North Carolina, Chapel Hill, North Carolina, USA

${ }^{3}$ Department of Epidemiology, Gillings School of Global Public Health, University of North Carolina, Chapel Hill, North Carolina, USA

${ }^{4}$ Division of Epidemiology and Biostatistics, Graduate School of Public Health, San Diego State University, San Diego, California, USA

${ }^{5}$ School of Media and Journalism, University of North Carolina, Chapel Hill, North Carolina, USA

Correspondence to Dr Noel T Brewer, Department of Health Behavior, Gillings School of Global Public Health, University of North Carolina, Chapel Hill NC 27599, USA; ntb@unc.edu

Received 20 October 2017 Revised 22 January 2018 Accepted 20 February 2018 Published Online First 13 April 2018

\begin{abstract}
Background The USA can require tobacco companies to disclose information about harmful and potentially harmful chemicals in cigarette smoke, but the impact of these messages is uncertain. We sought to assess the effect of placing messages about toxic chemicals on smokers' cigarette packs.

Methods Participants were 719 adult cigarette smokers from California, USA, recruited from September 2016 through March 2017. We randomly assigned smokers to receive either factual messages about chemicals in cigarette smoke and their health harms (intervention) or messages about not littering cigarette butts (control) on the side of their cigarette packs for 3 weeks. The primary trial outcome was intention to quit smoking.

Results In intent-to-treat analyses, smokers whose packs had chemical messages did not have higher intentions to quit smoking at the end of the trial than those whose packs had control messages $(P=0.56)$. Compared with control messages, chemical messages led to higher awareness of the chemicals ( $28 \%$ vs $15 \%, P<0.001)$ and health harms $(60 \%$ vs $52 \%$, $\mathrm{P}=0.02$ ) featured in the messages. In addition, chemical messages led to greater negative affect, thinking about the chemicals in cigarettes and the harms of smoking, conversations about the messages and forgoing a cigarette (all $\mathrm{P}<0.05$ ).
\end{abstract}

Discussion Chemical messages on cigarette packs did not lead to higher intentions to quit among smokers in our trial. However, chemical messages informed smokers of chemicals in cigarettes and harms of smoking, which directly supports their implementation and would be critical to defending the messages against cigarette company legal challenges.

Trial registration number NCT02785484.

\section{INTRODUCTION}

Burning the tobacco in cigarettes creates and concentrates harmful and potentially harmful constituents (chemicals) that smokers inhale. ${ }^{1}$ Toxic chemicals and particulate matter in cigarette smoke cause 480000 deaths a year in the USA, ${ }^{2}$ primarily from cancer, cardiovascular disease and respiratory disease. ${ }^{3}$ However, few people fully understand these risks. The majority of US adults incorrectly believe that most harmful chemicals in cigarette smoke come from tobacco additives, and a third incorrectly believe that cigarette filters remove 'a lot' of these chemicals. ${ }^{5}$ Helping people understand how smoking puts their health at risk and motivating them to quit smoking are two compelling public health goals that effective communication with smokers could help to achieve. ${ }^{6}$

Messages on cigarette packs have high reach because smokers see their packs many times a day. ${ }^{7-10}$ Over 100 countries require pictorial cigarette pack warnings, ${ }^{11}$ which effectively inform smokers about the health risks of smoking ${ }^{9}$ and increase quit attempts. ${ }^{12}$ The US Family Smoking Prevention and Tobacco Control Act requires the front and back of cigarette packs to have pictorial warnings, ${ }^{13}$ which the tobacco industry has stalled through litigation. ${ }^{14}$ The Tobacco Control Act also empowers the US government to implement messages about toxic chemicals in cigarette smoke anywhere on cigarette packs. ${ }^{13}$ In the past, when US cigarette packs displayed the amount of tar and nicotine, comparisons across brands created the illusion of reduced risk that misled consumers. ${ }^{15-17}$ Thus, countries have moved away from including quantitative information about chemicals in messages on packs. ${ }^{18} 19$ Several countries including Mexico, Canada and Australia instead require descriptive, non-numerical chemical messages on cigarette packs, which have been associated with increases in knowledge of these chemicals. ${ }^{20}$ The USA has yet to identify chemical messages or methods for disclosure. ${ }^{21}$ The USA will likely have to defend any required new chemical messages against legal challenges by the tobacco industry. To establish evidence relevant to implementation of chemical messages, we evaluated them in a randomised clinical trial (RCT). We tested our hypothesis that messages on cigarette packs disclosing information about the presence of toxic chemicals in cigarette smoke would motivate smokers to quit. We also examined whether such chemical messages informed smokers.

\section{METHODS}

\section{Participants}

Participants in the RCT were adult smokers from the general population in the Bay Area in California, USA. Eligibility criteria were being age 21 years or older; being a current smoker (defined as having smoked at least 100 cigarettes and currently smoking every day or some days); smoking at least seven cigarettes per week (to exclude very light smokers who might not purchase their own packs); being able to attend five weekly appointments; being able to bring in 8 days' worth of cigarettes to each of the first four weekly visits; and being able to speak English and use a computer to take surveys. We excluded pregnant women from the trial, as well as smokers who used only roll-your-own cigarettes, 


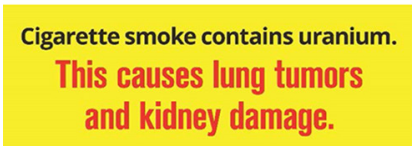

\section{Cigarette smoke contains arsenic. This causes heart damage.}

Cigarette smoke contains formaldehyde. This causes throat cancer.

Figure 1 Labels placed on smokers' cigarette packs in intervention arm (A) and control arm (B).

were concurrently enrolled in another tobacco study or lived in the same household as another trial participant. We recruited participants between September 2016 and March 2017 through craigslist, Facebook, in-person recruitment and newspaper advertisements. We screened potential participants for eligibility online and by phone.

\section{Procedures}

Trial design

We conducted a parallel group RCT. Each smoker received a label on the side of his or her cigarette packs for a total of 3 weeks. We chose this exposure period because it allowed for sufficient time to observe an effect on our primary outcome of quit intentions based on our previous pictorial warnings trial. ${ }^{12}$ Smokers in the intervention arm saw a different label every week, in one of the six possible orders. The control arm followed the same procedure. We chose to label the sides of packs for a conservative estimate of the messages' impact and because the USA might be more likely to place them on the side of packs since pictorial warnings are already required to appear on the front and back of packs.

\section{Message development}

We developed chemical (intervention) and litter (control) messages through a multistage process. First, we systematically reviewed the literature on how people think about the chemicals in cigarette smoke. ${ }^{16}$ Second, we conducted focus groups on what adults and adolescents believed about chemicals in cigarette smoke. ${ }^{22}$ Third, we conducted national surveys to identify chemicals and health effects that smokers thought would discourage them from wanting to smoke. ${ }^{5} 2324$ Fourth, we developed 76 chemical messages and conducted national surveys to evaluate the perceived effectiveness of these messages. ${ }^{25} 26$ Fifth, we conducted focus groups to vet the nine most promising chemical messages to ensure that people brought the same meaning to the messages that we intended. ${ }^{27}$ Sixth, we evaluated the perceived effectiveness of six chemical messages in a survey with a national probability sample, retaining the three most promising ones for the intervention arm in the trial. ${ }^{27}$ Seventh, throughout the message development and testing process, we consulted toxicologists to confirm that the content of our messages was factual. The final chemical messages were 'Cigarette smoke contains formaldehyde. This causes throat cancer.'; 'Cigarette smoke contains uranium. This causes lung tumors and kidney damage.' and 'Cigarette smoke contains arsenic. This causes heart damage.'
Eighth, we developed three attention-matched control messages about not littering cigarette butts that mirrored the number and approximate length of words in the chemical messages. The final control messages were: 'Cigarette litter requires cleanup. Discard cigarette butts properly.'; 'Please refrain from littering. Cigarette butts are the most littered item.' and 'Cigarette butts don't biodegrade. Please do not litter.' Finally, we worked with a graphic design firm to develop labels that included the intervention and control messages, optimised for the side of cigarette packs. The intervention and control labels had the same layout, size and colour (figure 1). The control labels had a small white line on the bottom-right corner to distinguish from intervention labels during implementation.

\section{Trial protocol}

We adapted the UNC Pack Labeling Protocol, ${ }^{28}$ pilot tested it with 28 adult smokers and refined the protocol (online supplement 1). In our trial, we invited participants to attend five trial visits, each 1 week apart, at the trial office in San Francisco, California, USA. At visit 1, we confirmed eligibility, obtained written informed consent and enrolled smokers. Participants then and at each subsequent visit completed a computer survey.

We asked participants to bring 8 days' worth of cigarettes to visits $1-4$. While participants took the survey, research staff removed the cellophane from the packs and marked the bottom of the packs with the visit date. At visit 1, participants brought in their cigarette packs to demonstrate that they could adhere to the trial protocol, but we did not label the packs.

To randomise participants, a statistician generated a prepopulated list of assignments randomly ordered in blocks of 12 conditions ( 2 arms $\times 6$ label orders), prior to the start of the trial. This permuted block randomisation approach allowed the statistician to use a single allocation ratio to randomly assign smokers to 1 of 12 conditions while also maintaining balanced trial arms. When participants returned for visit 2 , study staff assigned them to condition using this list.

At visits 2-4, research staff applied a self-adhesive label with an intervention or control message to the right side of each participant's cigarette packs (ie, on the side opposite from the existing Surgeon General's warning), covering most of that side. Participants who missed a visit after randomisation were able to complete the corresponding survey online; participants who missed visits 3 or 4 did not have their packs labelled for that week. At the end of each visit, on completion of the survey, participants received a cash incentive that totalled up to $\$ 300$ across the trial. At the end of the trial, we offered participants information and resources about smoking cessation.

The trial's registration is available at clinicaltrials.gov, identifier NCT02785484.

\section{Measures}

A survey at visit 5 assessed the trial outcomes (eTable 1 in online supplement 2). The primary trial outcome was intention to quit smoking, assessed using a three-item scale that has high reliability $^{12} 29$ and correlates with smoking behaviour (Brewer et al, under review). The first item was, 'How interested are you in quitting smoking in the next month?', with responses that ranged from 'not at all interested' (coded as 1) to 'very interested' (4). The second item was, 'How much do you plan to quit smoking in the next month?', with responses that ranged from 'not at all' (1) to 'very much' (4). The third item was, 'How likely are you to quit smoking in the next month?', with responses that ranged from 'not at all likely' (1) to 'very likely' (4). We averaged these 
intention items to create an intention score that ranged from 1 to 4 (Cronbach's a=0.94).

We conceptualised secondary trial outcomes related to being informed as a continuum from having heard information to actively thinking about it and changing one's risk beliefs. Measures of being informed were awareness of chemicals in cigarette smoke (ie, arsenic, uranium, formaldehyde) and health effects of smoking (ie, lung tumours, throat cancer, kidney damage, heart damage) that were in the intervention messages; awareness of chemicals (ie, ammonia, benzene, lead) and health effects (ie, lip cancer, strokes) not in the messages; thinking about the chemicals in cigarette smoke, the harms of smoking, the messages and quitting ${ }^{30} 31$; and perceived likelihood of smoking-related illnesses mentioned in the intervention messages (absolute chance of harm to the respondent). ${ }^{12}$ We conceptualised secondary trial outcomes related to motivation as constructs that predict quitting smoking, based on the UNC Tobacco Warning Model (Brewer et al, under review) and other models $^{32} 33$ as well as prior empirical research. ${ }^{34-37}$ Measures of motivators were negative affect (ie, fear, anxiety, disgust, sadness, guilt $)^{38-40}$; number of conversations about the label in the past week $^{4142}$; number of times butting out or forgoing a cigarette in the past week ${ }^{4344}$; attempt to quit smoking for 1 day or longer in the past 3 weeks, which included weekly and end-of-trial recall of quit attempts ${ }^{45}$; and quitting smoking (ie, did not smoke in the past 7 days as of the end of the trial). ${ }^{46}$ We conceptualised thinking about the messages and their implications as related to both being informed and motivated.

The visit 1 survey assessed many of the same outcomes as well as participant demographics and smoking behaviours. Most survey items were previously validated; we cognitively tested newly developed measures either in person $(n=7)$ or online $(n=311)$.

\section{Statistical analysis}

Power analyses showed that enrolling 672 smokers would provide $>80 \%$ power to detect a difference in quit intentions of $d=0.22$ (a small effect) or larger in analyses with $\alpha=0.05$. To check whether random assignment created trial arms that were equivalent on demographic and outcome variables at visit 2 (the randomisation visit), we used $\chi^{2}$ tests for categorical variables and t-tests for continuous variables. We used logistic regression to assess differential attrition.

Intention-to-treat analyses ${ }^{47}$ of trial outcomes included all smokers randomised to trial arms $(n=719)$. For smokers lost to follow-up, we used the last observation available to fill in any missing outcome values, allowing us to maintain the sample size and power of the study. We examined the effect of trial arm on the primary trial outcome (intentions to quit smoking) using linear regression. To assess whether the impact of trial arm differed among subgroups, exploratory analyses used linear regression models with interaction terms between trial arm and demographics or smoking frequency. We examined whether secondary outcomes differed by trial arms using $\chi^{2}$ tests for dichotomous variables and t-tests for continuous variables. We did not plan or conduct interim analyses or other analyses beyond those reported here. Analyses used two-tailed tests in Stata V.14 (StataCorp, 2015) with a critical alpha of .05.

\section{RESULTS}

\section{Participant characteristics}

From September 2016 to March 2017, 784 adult current smokers enrolled in the trial (figure 2). We randomised all 719 smokers who returned to visit 2 (368 men, 320 women and 31 transgender people). Smokers in the trial were diverse, including a substantial number of African American, sexual minority, low-education, and low-income smokers (table 1). The trial arms

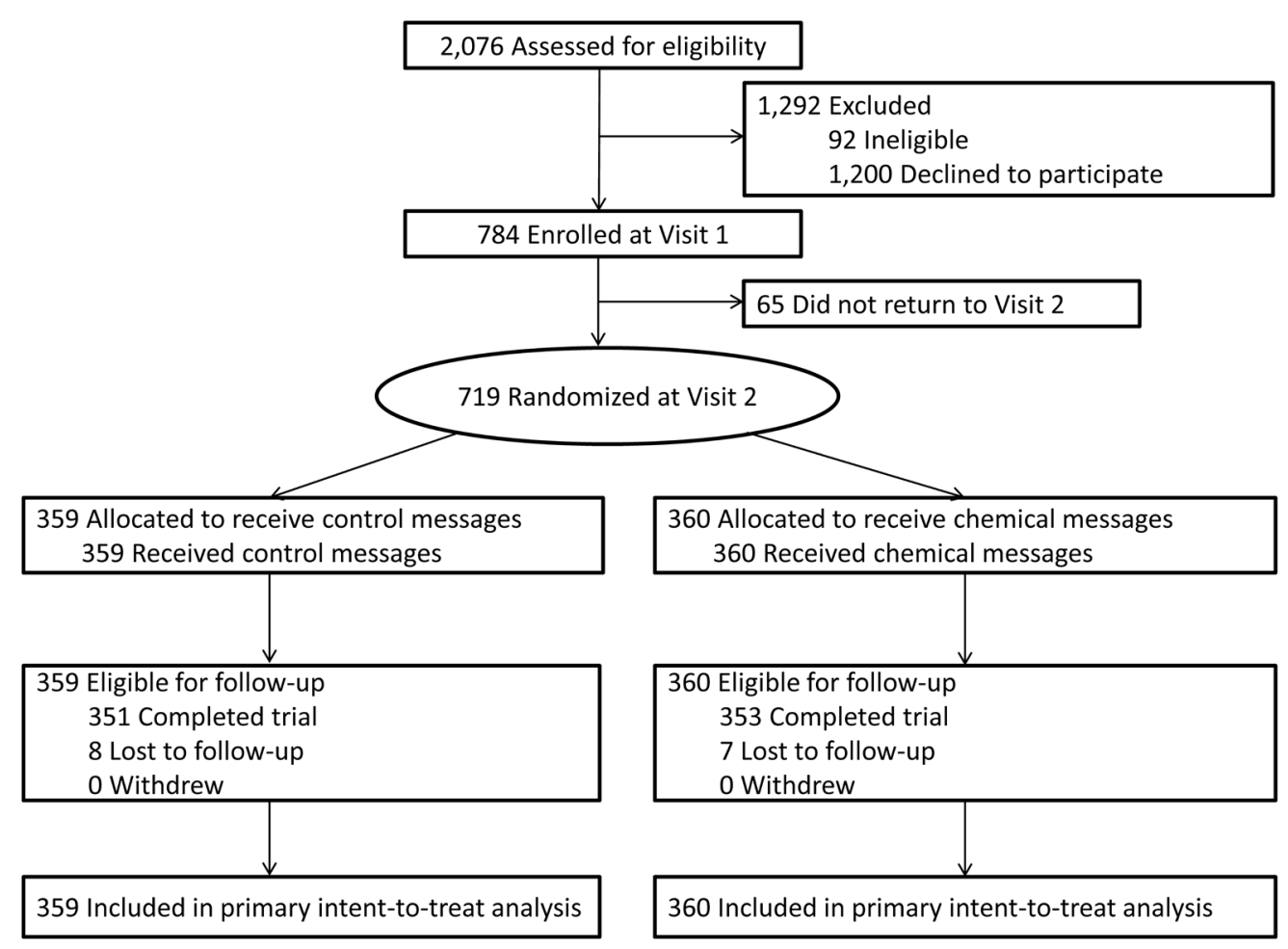

Figure 2 Flow diagram of trial enrollment, randomisation and retention. 


\begin{tabular}{|c|c|c|}
\hline & $\begin{array}{l}\text { Control messages } \\
(n=359)\end{array}$ & $\begin{array}{l}\text { Chemical messages } \\
(n=360)\end{array}$ \\
\hline & $\mathrm{n}(\%)$ & n (\%) \\
\hline \multicolumn{3}{|l|}{ Age (years) } \\
\hline $21-29$ & $81(22.6)$ & $83(23.1)$ \\
\hline $30-39$ & $86(24.0)$ & $78(21.7)$ \\
\hline $40-49$ & $59(16.4)$ & $75(20.8)$ \\
\hline $50-59$ & $90(25.1)$ & $91(25.3)$ \\
\hline $60+$ & $43(12.0)$ & $33(9.2)$ \\
\hline Mean (SD) & $42.8(13.6)$ & $42.1(13.2)$ \\
\hline \multicolumn{3}{|l|}{ Gender } \\
\hline Male & $172(47.9)$ & $196(54.4)$ \\
\hline Female & $169(47.1)$ & $151(41.9)$ \\
\hline $\begin{array}{l}\text { Transgender (includes other } \\
\text { gender identity) }\end{array}$ & $18(5.0)$ & $13(3.6)$ \\
\hline Gay, lesbian or bisexual & $88(24.5)$ & $93(25.8)$ \\
\hline Hispanic & $56(15.6)$ & $44(12.2)$ \\
\hline \multicolumn{3}{|l|}{ Race } \\
\hline White & $136(37.9)$ & $132(36.7)$ \\
\hline Black or African American & $124(34.5)$ & $133(36.9)$ \\
\hline Asian & $29(8.1)$ & $31(8.6)$ \\
\hline $\begin{array}{l}\text { American Indian or Alaska } \\
\text { Native }\end{array}$ & $17(4.7)$ & $17(4.7)$ \\
\hline $\begin{array}{l}\text { Native Hawaiian or other } \\
\text { Pacific Islander }\end{array}$ & $11(3.1)$ & $12(3.3)$ \\
\hline Other/multiracial & $42(11.7)$ & $35(9.7)$ \\
\hline \multicolumn{3}{|l|}{ Education } \\
\hline High school graduate or less & $67(18.7)$ & $89(24.7)$ \\
\hline Some college & $151(42.1)$ & $124(34.4)$ \\
\hline College graduate & $114(31.8)$ & $122(33.9)$ \\
\hline Graduate degree & $27(7.5)$ & $25(6.9)$ \\
\hline \multicolumn{3}{|l|}{ Household income, annual \$ } \\
\hline 0-24999 & $154(42.9)$ & $170(47.2)$ \\
\hline $25000-49999$ & $88(24.5)$ & $89(24.7)$ \\
\hline $50000-74999$ & $53(14.8)$ & $35(9.7)$ \\
\hline $75000+$ & $64(17.8)$ & $66(18.3)$ \\
\hline $\begin{array}{l}\text { Low income, }<200 \% \text { of federal } \\
\text { poverty level }\end{array}$ & $197(54.9)$ & $216(60.0)$ \\
\hline $\begin{array}{l}\text { Cigarettes smoked per day, mean } \\
\text { (SD) }\end{array}$ & $9.97(12.2)$ & $11.62(16.9)$ \\
\hline \multicolumn{3}{|l|}{ Smoking frequency } \\
\hline Daily & $273(76.0)$ & $281(78.1)$ \\
\hline Non-daily & $86(24.0)$ & $79(21.9)$ \\
\hline $\begin{array}{l}\text { E-cigarette use in the past } \\
3 \text { weeks }\end{array}$ & $95(26.5)$ & $94(26.2)$ \\
\hline $\begin{array}{l}\text { Other tobacco product use in } \\
\text { the past } 3 \text { weeks }\end{array}$ & $149(41.5)$ & $139(38.6)$ \\
\hline \multicolumn{3}{|l|}{ Primary trial outcome at baseline } \\
\hline $\begin{array}{l}\text { Intended to quit smoking in the } \\
\text { next month, mean (SD) }\end{array}$ & $2.36(1.0)$ & $2.37(0.9)$ \\
\hline \multicolumn{3}{|l|}{ Secondary trial outcomes at baseline } \\
\hline $\begin{array}{l}\text { Made quit attempt (for } \\
24 \text { hours) in the past } 3 \text { weeks* }\end{array}$ & $96(26.7)$ & $91(25.3)$ \\
\hline Quit smoking for $\geq 7$ days & $8(2.2)$ & $6(1.7)$ \\
\hline $\begin{array}{l}\text { Number of times forgoing/ } \\
\text { butting out a cigarette in } \\
\text { the past week, mean (SD) } \dagger\end{array}$ & $4.9(4.6)$ & $5.3(4.8)$ \\
\hline $\begin{array}{l}\text { Thinking about the harms of } \\
\text { smoking, mean (SD) }\end{array}$ & $2.9(1.1)$ & $2.8(1.0)$ \\
\hline
\end{tabular}

Table 1 Continued

\begin{tabular}{|c|c|c|}
\hline & $\begin{array}{l}\text { Control messages } \\
(n=359)\end{array}$ & $\begin{array}{l}\text { Chemical messages } \\
(n=360)\end{array}$ \\
\hline & n (\%) & n (\%) \\
\hline $\begin{array}{l}\text { Thinking about quitting, mean } \\
\text { (SD) }\end{array}$ & $2.8(1.3)$ & $2.8(1.2)$ \\
\hline $\begin{array}{l}\text { Thinking about the chemicals in } \\
\text { cigarettes, mean (SD) }\end{array}$ & $2.6(1.3)$ & $2.5(1.2)$ \\
\hline \multicolumn{3}{|c|}{$\begin{array}{l}\text { Participant characteristics and outcomes did not differ by trial arm at baseline } \\
\text { (all P>0.05). Baseline surveys did not assess awareness of health effects (on or } \\
\text { not on labels), awareness of chemicals (on or not on labels), thinking about the } \\
\text { message, negative affect, perceived likelihood of harm from smoking and number } \\
\text { of conversations about the label. For thinking about the harms of smoking, baseline } \\
\text { surveys included two of the three items (thinking about harms to self and harms } \\
\text { to others) but not the third item on thinking about health problems caused by } \\
\text { smoking. } \\
\text { *Quit attempts in the past three weeks were assessed at enrolment. } \\
\text { tSummed score, ranging from } 0 \text { to } 20 \text {, reflecting number of times forgoing a } \\
\text { cigarette and number of times butting out a cigarette. }\end{array}$} \\
\hline
\end{tabular}

(359 smokers received control messages about littering and 360 received intervention messages about toxic chemicals in cigarette smoke) did not differ with respect to demographic characteristics and baseline values for primary and secondary outcomes (table 1). Participants attended and had their cigarette packs labelled at an average of 2.9 of 3 trial visits. Analyses of attrition showed that $98 \%$ of participants $(n=704)$ completed the final visit and survey. Fifteen participants were lost to follow-up; no participant withdrew from the trial. Attrition did not differ by trial arm $(\mathrm{P}=0.79)$. Attrition also did not differ by demographic characteristics across trial arms except for income $(\mathrm{P}<0.05$ for interaction); low-income smokers in the intervention arm and high-income smokers in the control arm were less likely to complete the visit 5 survey. No participant reported adverse events during the trial.

\section{Motivating quitting}

The intervention and control arms did not differ on the primary trial outcome, intentions to quit smoking, at the end of the trial (table 2). Smokers who received chemical messages had mean quit intentions of 2.6 (SD 1.0), and smokers who received litter messages had mean quit intentions of 2.6 (SD 1.1, $\mathrm{P}=0.56$ ). In exploratory analyses, the effect of trial arm on quit intentions did not differ among the demographic subgroups we examined ( $P>0.38$ for all interactions; eTable 2 in online supplementary 2 ); the effect of trial arm on quit intentions differed by smoking frequency but not after controlling for baseline quit intentions.

With respect to motivators of quitting, intervention messages led to more negative affect $(\mathrm{P}<0.001)$ and more conversations about the messages $(\mathrm{P}=0.04)$. Forgoing a cigarette in the past week was more common in the chemical message arm than litter message arm (mean $(\mathrm{SD})=6.6(5.6)$ vs $5.6(5.1)$ times, $\mathrm{P}=0.02$; table 2). Trial arms did not differ on quit attempts or quitting, outcomes the trial was not powered to detect.

\section{Increasing understanding}

Exposure to chemical messages led to greater awareness of the chemicals $(28 \%$ vs $15 \%, \mathrm{P}<0.001)$ and health effects $(60 \%$ vs $52 \%, \mathrm{P}=0.02)$ mentioned in the intervention messages than did the litter messages. Trial arms did not differ with respect to awareness of chemicals and health effects not in the intervention messages. Exposure to chemical messages also led to more thinking about the chemicals in cigarettes $(\mathrm{P}=0.002)$ and about 
Table 2 Trial outcomes at visit 5, intent-to-treat analysis

\begin{tabular}{|c|c|c|c|c|c|c|}
\hline & \multicolumn{2}{|c|}{$\begin{array}{l}\text { Control messages } \\
(\mathrm{n}=359)\end{array}$} & \multicolumn{2}{|c|}{$\begin{array}{l}\text { Chemical messages } \\
(n=360)\end{array}$} & \multirow[b]{2}{*}{ Difference $(95 \% \mathrm{Cl})$} & \multirow[b]{2}{*}{$P$ values } \\
\hline & $n$ & Mean (SD) & $n$ & Mean (SD) & & \\
\hline \multicolumn{7}{|l|}{ Primary outcome } \\
\hline Quit intentions* & 359 & $2.6(1.1)$ & 360 & $2.6(1.0)$ & $0.05(-0.11$ to 0.20$)$ & 0.56 \\
\hline \multicolumn{7}{|l|}{ Secondary outcomes } \\
\hline Negative affect†‡ & 351 & $2.0(1.0)$ & 350 & $2.4(1.1)$ & 0.34 (0.18 to 0.49$)$ & $<0.001$ \\
\hline The harms of smokingt & 359 & $2.8(1.1)$ & 360 & $3.0(1.0)$ & $0.17(0.02$ to 0.33$)$ & 0.03 \\
\hline The messaget‡ & 351 & $2.6(1.1)$ & 353 & $2.7(1.1)$ & $0.01(-0.15$ to 0.17$)$ & 0.88 \\
\hline Quitting & 359 & $3.1(1.4)$ & 360 & $3.1(1.2)$ & $0.03(-0.16$ to 0.22$)$ & 0.75 \\
\hline Perceived likelihood of harm from smoking $\dagger$ & 359 & $3.1(0.9)$ & 360 & $3.2(0.9)$ & $0.03(-0.09$ to 0.16$)$ & 0.62 \\
\hline Number of conversations about label in the past week & 359 & $1.9(3.3)$ & 360 & $2.5(4.2)$ & 0.57 (0.02 to 1.12$)$ & 0.04 \\
\hline Chemicals in intervention messages§ & 359 & 15.0 & 360 & 28.1 & 13.01 (7.08 to 18.95$)$ & $<0.001$ \\
\hline Health effects in intervention messages§ & 359 & 51.8 & 360 & 60.3 & $8.47(1.24$ to 15.70$)$ & 0.02 \\
\hline Chemicals not in intervention messages§ & 359 & 16.2 & 360 & 13.6 & $-2.54(-7.75$ to 2.66$)$ & 0.34 \\
\hline Health effects not in intervention messages§ & 359 & 48.2 & 360 & 43.9 & $-4.30(-11.58$ to 2.98$)$ & 0.25 \\
\hline Made quit attempt (for 24 hours) in the past 3 weeks & 359 & 41.8 & 360 & 41.4 & $-0.39(-7.60$ to 6.81$)$ & 0.92 \\
\hline Quit smoking for $\geq 7$ days & 359 & 7.0 & 360 & 5.8 & $-1.13(-4.71$ to 2.45$)$ & 0.54 \\
\hline
\end{tabular}

Outcomes were assessed by survey at the final trial visit.

* Response scale for quit intentions ranged from 1 to 4 , with 4 indicating highest intentions.

tResponse scale for negative affect, thinking about the chemicals in cigarettes, thinking about the harms of smoking, thinking about the message, thinking about quitting and perceived likelihood of harm from smoking ranged from 1 to 5 , with 5 indicating higher quantity or stronger endorsement.

¥Negative affect and thinking about the message were not assessed until week 3 follow-up, resulting in a smaller $\mathrm{n}$ for these analyses.

$\S$ Had heard of at least half of the chemicals being in cigarette smoke or their health effects, in a 2-to-4-item index.

the harms of smoking $(\mathrm{P}=0.03)$. Trial arms did not differ on thinking about the message, thinking about quitting or perceived likelihood of harm.

\section{DISCUSSION}

Government agencies regularly require disclosures about potential product harms, but the impact of such disclosures on the public is poorly understood. ${ }^{6}$ In our randomised trial with adult smokers, chemical messages on cigarette packs did not increase motivation to quit smoking as measured by quit intentions. This is in contrast to pictorial cigarette pack warnings, which increase quit intentions, quit attempts and successful quitting. ${ }^{12}$ One explanation for the difference is that pictorial warnings caused large increases in negative affect as well as thinking and talking about the messages, whereas chemical messages had only

Table 3 Impact of chemical messages and pictorial warnings

\begin{tabular}{|c|c|c|}
\hline & $\begin{array}{l}\text { Effect size for chemical } \\
\text { messages (d) }\end{array}$ & $\begin{array}{l}\text { Effect size for pictorial } \\
\text { warnings }(d)^{12}\end{array}$ \\
\hline Negative affect & Medium (0.31) & Large (0.54) \\
\hline $\begin{array}{l}\text { Thinking about the harms of } \\
\text { smoking }\end{array}$ & Small (0.15) & Small (0.18) \\
\hline Thinking about the message & Small (0.01) & Large (0.61) \\
\hline $\begin{array}{l}\text { Perceived likelihood of harm from } \\
\text { smoking }\end{array}$ & Small (0.04) & Small $(0.00)$ \\
\hline $\begin{array}{l}\text { Number of conversations about label } \\
\text { in the past week }\end{array}$ & Small (0.15) & Medium (0.26) \\
\hline Quit intentions & Small (0.04) & Small (0.18) \\
\hline
\end{tabular}

a modest impact on these outcomes (table 3). ${ }^{12}$ Affective reactions bring meaning and importance to facts. ${ }^{48-51}$ Facts presented plainly, as in our messages, may not adequately trigger the kinds of emotional, cognitive and interpersonal responses necessary to motivate smokers to quit. Other potential explanations are that text-based chemical messages are not as vivid as pictorial warnings, and the placement of chemical messages on the side of the pack may reduce their impact. Pictorial warnings, ${ }^{12}$ and the chemical messages in our trial, increased forgoing a cigarette, perhaps reflecting a brief and transitory behavioural impact of the messages that might influence future cessation based on prior research about micro-indicators of quitting. ${ }^{365253}$

Chemical messages in our trial were, however, successful in informing smokers about chemicals in cigarette smoke. Although the chemical messages in our trial did not increase perceived likelihood of harm from smoking, neither do pictorial warnings. ${ }^{10} 1254$ Awareness increased for the chemicals and health effects mentioned in the chemical messages - and awareness did not change for other chemicals and health effects not mentioned. Chemical messages also increased thinking about chemicals in cigarette smoke and the harms of smoking. These findings are important given that US smokers have low awareness of the many chemicals in cigarette smoke. ${ }^{516}$ Chemical messages may fill gaps in knowledge and increase understanding about these toxic chemicals, new information that the public is interested in receiving. ${ }^{165}$ Another way to inform smokers about the many risks associated with smoking is a media campaign about chemicals in cigarette smoke. ${ }^{56}$ Government media campaigns face fewer legal constraints than messages required on cigarette packs. Campaigns can also communicate about chemicals in 
more active and vivid ways that are potentially more impactful, as the USA is doing as part of The Real Cost campaign that targets at-risk youth. ${ }^{57} 58$

In the likely event of a cigarette company lawsuit challenging any government-required chemical messages on packs, the US government would have to demonstrate that it acted within its legal authority. The Tobacco Control Act permits the US FDA Center for Tobacco Products to require cigarette packs to have chemical messages that would protect public health, benefit public health or 'increase consumer awareness of the health consequences of the use of tobacco products'. ${ }^{13}$ In our trial, chemical messages increased awareness of chemicals in cigarette smoke and of the harms of smoking. Thus, our findings would support government action to require chemical messages on cigarette packs.

The government would also have to demonstrate that requiring chemical messages does not violate First Amendment constraints on regulating commercial speech. ${ }^{14}$ Courts could make the government establish that the chemical messages plausibly advance a legitimate interest. ${ }^{59}$ The increase in awareness in our trial shows that requiring such messages would advance the government interest of informing smokers. In addition, courts could make the government demonstrate that the chemical messages are 'factual and uncontroversial. ${ }^{59}$ The messages in our trial are both factual and uncontroversial, as confirmed by scientists with expertise in toxic chemicals and their health consequences, as well as by legal scholars with expertise in public health and the First Amendment. An intriguing possibility is that pairing pictorial health warnings with chemicals messages on cigarette packs could act synergistically to better inform and motivate smokers beyond what either do on their own. However, it is also possible that putting both chemical messages and pictorial health warnings on packs could detract from the effectiveness of pictorial warnings. Future studies should assess their joint impact.

Trial strengths include a large sample of diverse smokers who received carefully developed messages on their cigarette packs for 3 weeks. Other strengths include random assignment and control messages matched for size, colour, word length and location on the pack, allowing us to isolate the effects of the chemical message content. The generalisability of these findings to youth and non-smokers has yet to be established given that our trial enrolled only adult smokers, although our developmental findings were promising for these groups. Similarly, it will be helpful to replicate the findings in other locales with different tobacco control policies and norms surrounding smoking and outside the context of a clinical trial. Studies of the impact of chemical messages over the course of months or years could offer new insights on how to counter the waning impact of tobacco warnings over time, ${ }^{37}$ 60-62 which necessitates regular implementation of novel messages.

\section{CONCLUSIONS}

Our findings suggest that chemical messages on the side of cigarette packs could advance the US government interest of informing smokers, supporting their implementation. However, in our trial, chemical messages did not increase quit intentions and therefore do not appear to motivate quitting smoking. The extent to which pictorial warnings and chemical messages work in a complementary manner to reinforce one another is an important area for future study. ${ }^{63}$

Acknowledgements The authors thank the staff at Ewald \& Wasserman Research Consultants LLC, Trent Johnson, MPH, and Jessica Pepper, PhD, for their assistance with the trial; and Micah Berman, JD, and Eric Lindblom, JD, for their feedback on the manuscript. They received no compensation for their contributions beyond that received in the normal course of their employment.
What this paper adds

- The US Tobacco Control Act allows cigarette packs to have messages about toxic chemicals in cigarette smoke. Data do not yet show whether such messages help people understand how smoking puts their health at risk or motivates them to quit smoking.

- Chemical messages on the side of cigarette packs did not lead to higher intentions to quit in a randomised clinical trial with 719 adult smokers in California, USA.

- However, chemical messages informed smokers of chemicals in cigarette smoke and harms of smoking.

Contributors NTB had full access to all of the data in the study and takes responsibility for the integrity of the data and the accuracy of the data analysis. Study concept and design: NTB, MHB, JRM, MGH, SMN, SAB, JCM and KMR. Acquisition, analysis or interpretation of data: NTB, MJ, DZ, HP and MHB. Drafting of the manuscript: NTB, MJ, JRM and MGH. Critical revision of the manuscript for important intellectual content: all authors. Statistical analysis: NTB, MJ, DZ and MHB. Obtained funding: NTB, MGH, SMN and KMR. Administrative, technical or material support: NTB, MJ, JRM, MGH, HP, SAB, JCM and KMR. Study supervision: NTB and JRM.

Funding Research reported in this publication was supported by grant number P50CA180907 from the National Cancer Institute and FDA Center for Tobacco Products (CTP). T32CA057726 from the National Cancer Institute of the National Institutes of Health supported MGH's time writing the paper.

Disclaimer The content is solely the responsibility of the authors and does not necessarily represent the official views of the NIH or the Food and Drug Administration. The funding institutions had no role in the design and conduct of the study; collection, management, analysis and interpretation of the data; preparation, review or approval of the manuscript; and decision to submit the manuscript for publication.

Competing interests None of the authors have received funding from tobacco product manufacturers. NTB and KMR have served as paid expert consultants in litigation against tobacco companies. The other authors declare no conflicts of interest.

\section{Patient consent Obtained.}

Ethics approval The University of North Carolina institutional review board approved the trial procedures.

Provenance and peer review Not commissioned; externally peer reviewed.

Data sharing statement Due to our university's requirements on grantfunded research, we can share the study data with a signed data use agreement. Investigators wishing to access the data may contact the first or last author of the paper.

Open access This is an open access article distributed in accordance with the Creative Commons Attribution Non Commercial (CC BY-NC 4.0) license, which permits others to distribute, remix, adapt, build upon this work non-commercially, and license their derivative works on different terms, provided the original work is properly cited and the use is non-commercial. See: http://creativecommons.org/ licenses/by-nc/4.0/

(C) Article author(s) (or their employer(s) unless otherwise stated in the text of the article) 2019. All rights reserved. No commercial use is permitted unless otherwise expressly granted.

\section{REFERENCES}

1 Hecht SS. Research opportunities related to establishing standards for tobacco products under the Family Smoking Prevention and Tobacco Control Act. Nicotine Tob Res 2012;14:18-28.

2 Jamal A, Homa DM, O'Connor E, et al. Current cigarette smoking among adults United States, 2005-2014. MMWR Morb Mortal Wkly Rep 2015;64:1233-40.

3 U.S. Department of Health and Human Services. The health consequences of smoking 550 years of progress: A report of the Surgeon General. Department of Health and Human Services, Centers for Disease Control and Prevention, National Center for Chronic Disease Prevention and Health Promotion, Office on Smoking and Health, 2014. Atlanta, GA: U.S, 2014.

4 International Agency for Research on Cancer. Tobacco smoke and involuntary smoking. Lyon, France, 2004. 
5 Parada H, Hall MG, Boynton MH, et al. Trajectories of responses to pictorial cigarette pack warnings. Nicotine Tob Res 2017. doi: 10.1093/ntr/ntx182. [Epub ahead of print 18 Aug 2017].

6 Brewer NT. Goals. In: Fischoff B, Brewer NT, Downs JS, eds. Communicating risks and benefits: An evidence-based user's guide. Washington, D.C: Food and Drug Administration, 2011:3-10.

7 Centers for Disease Control and Prevention (CDC). Health warnings on tobacco products - worldwide, 2007. MMWR Morb Mortal Wkly Rep 2009;58:528-9.

8 Noar SM, Francis DB, Bridges C, et al. Effects of strengthening cigarette pack warnings on attention and message processing: A systematic review. Journal Mass Commun Q 2017:94:416-442.

9 Noar SM, Francis DB, Bridges C, et al. The impact of strengthening cigarette pack warnings: Systematic review of longitudinal observational studies. Soc Sci Med 2016;164:118-29

10 Noar SM, Hall MG, Francis DB, et al. Pictorial cigarette pack warnings: a meta-analysis of experimental studies. Tob Control 2016;25:341-54.

11 Canadian Cancer Society. Cigarette package health warnings: International status report. 5th ed. Canada: Ontario Canadian Cancer Society, 2016.

12 Brewer NT, Hall MG, Noar SM, et al. Effect of Pictorial Cigarette Pack Warnings on Changes in Smoking Behavior: A Randomized Clinical Trial. JAMA Intern Med 2016;176:905-12.

13 United States Public Laws. Family smoking prevention and tobacco control act of 2009. 111th Congress, 1st Session. Public Law 111531 [H.R. 1256]. 2009.

14 Kraemer JD, Baig SA. Analysis of legal and scientific issues in court challenges to graphic tobacco warnings. Am J Prev Med 2013;45:334-42.

15 National Cancer Institute. Risks associated with smoking cigarettes with low machinemeasured yields of tar and nicotine. Smoking and Tobacco Control Monograph 13. Bethesda, MD: US Department of Health and Human Services, National Institutes of Health, National Cancer Institute, 2001

16 Morgan JC, Byron MJ, Baig SA, et al. How people think about the chemicals in cigarette smoke: a systematic review. J Behav Med 2017;40:553-64.

17 Gilpin EA, Emery S, White MM, et al. Does tobacco industry marketing of 'light' cigarettes give smokers a rationale for postponing quitting? Nicotine Tob Res 2002:4:147-55.

18 Salloum RG, Louviere JJ, Getz KR, et al. Evaluation of strategies to communicate harmful and potentially harmful constituent (HPHC) information through cigarette package inserts: a discrete choice experiment. Tob Control 2018;27:677-83.

19 Hammond D, White CM. Improper disclosure: tobacco packaging and emission labelling regulations. Public Health 2012;126:613-9.

20 Cho YJ, Thrasher JF, Swayampakala K, et al. Does Adding Information on Toxic Constituents to Cigarette Pack Warnings Increase Smokers' Perceptions About the Health Risks of Smoking? A Longitudinal Study in Australia, Canada, Mexico, and the United States. Health Educ Behav 2018;45:32-42.

21 Hammond D. Tobacco labelling and packaging toolkit. 2009. http://www. tobaccolabels.ca/toolkit (accessed 10 Dec 2012)

22 Moracco KE, Morgan JC, Mendel J, et al. "My First Thought was Croutons": Perceptions of Cigarettes and Cigarette Smoke Constituents Among Adult Smokers and Nonsmokers. Nicotine Tob Res 2016;18:1566-74.

23 Kelley DE, Boynton MH, Noar SM, et al. Effective Message Elements for Disclosures about Chemicals in Cigarette Smoke. Nicotine Tob Res 2017. doi: 10.1093/ntr/ntx109. [Epub ahead of print 17 May 2017].

24 Baig SA, Byron MJ, Boynton MH, et al. Communicating about cigarette smoke constituents: an experimental comparison of two messaging strategies. J Behav Med 2017:40:352-9.

25 Baig SA, Gottfredson NC, Noar SM, et al. UNC Perceived Message Effectiveness Scale: Development and Validation. In Preparation.

26 Noar SM, Kelley DE, Boynton MH, et al. Identifying principles for effective messages about chemicals in cigarette smoke. Prev Med 2018;106:31-7.

27 Baig SA, Moracco KE, Agans RP, et al. Testing message about cigarette smoke constituents: A mixed methods study. In Preparation.

28 Brewer NT, Hall MG, Lee JG, et al. Testing warning messages on smokers' cigarette packages: a standardised protocol. Tob Control 2016;25:153-9.

29 Klein WM, Zajac LE, Monin MM. Worry as a moderator of the association between risk perceptions and quitting intentions in young adult and adult smokers. Ann Behav Med 2009;38:256-61.

30 Borland $\mathrm{R}$, Yong $\mathrm{HH}$, Wilson $\mathrm{N}$, et al. How reactions to cigarette packet health warnings influence quitting: findings from the ITC Four-Country survey. Addiction 2009;104:669-75.

31 Hammond D, Fong GT, McDonald PW, et al. Impact of the graphic Canadian warning labels on adult smoking behaviour. Tob Control 2003;12:391-5.

32 Fong GT, Cummings KM, Borland R, et al. The conceptual framework of the International Tobacco Control (ITC) Policy Evaluation Project. Tob Control 2006;15:iii3-i ii11.

33 IARC. Handbooks of cancer prevention. Tobacco control: Methods for evaluating tobacco control policies. Lyon, France: International Agency for Research on Cancer, 2009

34 Yong $\mathrm{HH}$, Borland R, Thrasher JF, et al. Mediational pathways of the impact of cigarette warning labels on quit attempts. Health Psychol 2014;33:1410-20.
35 Sheeran P, Harris PR, Epton T. Does heightening risk appraisals change people's intentions and behavior? A meta-analysis of experimental studies. Psychol Bull 2014; 140:511-43.

36 Cho YJ, Thrasher JF, Yong HH, et al. Path analysis of warning label effects on negative emotions and quit attempts: A longitudinal study of smokers in Australia, Canada, Mexico, and the US. Soc Sci Med 2018;197.

37 Thrasher JF, Abad-Vivero EN, Huang L, et al. Interpersonal communication about pictorial health warnings on cigarette packages: Policy-related influences and relationships with smoking cessation attempts. Soc Sci Med 2016;164:141-9.

38 Nonnemaker J, Farrelly M, Kamyab K, et al; Experimental study of graphic cigarette warning labels: Final results report. Research Triangle Park, NC: RTI International, 2010.

39 Watson D, Clark LA, Tellegen A. Development and validation of brief measures of positive and negative affect: the PANAS scales. J Pers Soc Psychol 1988;54:1063-70.

40 Keller PA, Block LG. Increasing the Persuasiveness of Fear Appeals: The Effect of Arousal and Elaboration. J Consum Res 1996;22:448-59.

41 Hall MG, Peebles K, Bach LE, et al. Social Interactions Sparked by Pictorial Warnings on Cigarette Packs. Int J Environ Res Public Health 2015;12:13195-208.

42 Morgan JC, Southwell BG, Noar SM, et al. Frequency and Content of Conversations about Pictorial Warnings on Cigarette Packs. Nicotine Tob Res 2017. [Epub ahead of print 17 August 2017].

43 Borland R, Hill D. Initial impact of the new Australian tobacco health warnings on knowledge and beliefs. Tob Control 1997;6:317-25.

44 Li L, Borland R, Fong GT, et al. Smoking-related thoughts and microbehaviours, and their predictive power for quitting: findings from the International Tobacco Control (ITC) China Survey. Tob Control 2015:24:354-61.

45 Centers for Disease Control and Prevention. Adult Tobacco Survey (ATS, 2008.

46 Population Assessment of Tobacco and Health Study. PATH: Population Assessment of Tobacco and Health, 2014. http://www.pathstudyinfo.nih.gov/UI/HomeMobile.aspx. (accessed April 3 2014).

47 Brody T. Intent to treat analysis vs. per protocol analysis. Clinical trials: study design, endpoints and biomarkers, drug safety, and FDA and ICH guidelines. Cambridge, MA: Academic Press, 2011.

48 Peters E, Lipkus I, Diefenbach MA. The Functions of Affect in Health Communications and in the Construction of Health Preferences. J Commun 2006;56(suppl_1):S140 $-\$ 162$.

49 Goodman EP. Visual gut punch: persuasion, emotion, and the constitutional meaning of graphic disclosure. Cornell Law Rev 2014;99:513-70.

50 Witte K. Putting the fear back into fear appeals: The extended parallel process model. Commun Monogr 1992;59:329-49.

51 Wang AL, Lowen SB, Romer D, et al. Emotional reaction facilitates the brain and behavioural impact of graphic cigarette warning labels in smokers. Tob Control 2015:24:225-32

52 Partos TR, Borland R, Thrasher JF, et al. The predictive utility of micro indicators of concern about smoking: findings from the International Tobacco Control Four Country study. Addict Behav 2014;39:1235-42.

53 Li L, Borland R, Fong GT, et al. Smoking-related thoughts and microbehaviours, and their predictive power for quitting. Tob Control 2015;24:354-61.

54 Hall MG, Sheeran P, Noar SM, et al. Negative affect, message reactance and perceived risk: how do pictorial cigarette pack warnings change quit intentions? Tob Control 2018;27:e136-e142.

55 Crawford MA, Balch Gl, Mermelstein R. Tobacco Control Network Writing Group. Responses to tobacco control policies among youth. Tob Control 2002;11:14-19.

56 Brennan E, Durkin SJ, Cotter T, et al. Mass media campaigns designed to support new pictorial health warnings on cigarette packets: evidence of a complementary relationship. Tob Control 2011;20:412-8.

57 Duke JC, Alexander TN, Zhao X, et al. Youth's Awareness of and Reactions to The Real Cost National Tobacco Public Education Campaign. PLoS One 2015;10:e0144827.

58 Huang LL, Lazard AJ, Pepper JK, et al. Impact of The Real Cost Campaign on Adolescents' Recall, Attitudes, and Risk Perceptions about Tobacco Use: A National Study. Int J Environ Res Public Health 2017;14:42.

59 American Meat Institute vs United States Department of Agriculture. Case No. 135281: United States Court of Appeals, District of Columbia Circuit, 2014

60 Hammond D, Fong GT, Borland R, et al. Text and graphic warnings on cigarette packages: findings from the international tobacco control four country study. Am J Prev Med 2007:32:202-9.

61 Hitchman SC, Driezen P, Logel C, et al. Changes in effectiveness of cigarette health warnings over time in Canada and the United States, 2002-2011. Nicotine Tob Res 2014; 16:536-43

62 Swayampakala K, Thrasher J, Carpenter MJ, et al. Level of cigarette consumption and quit behavior in a population of low-intensity smokers--longitudinal results from the International Tobacco Control (ITC) survey in Mexico. Addict Behav 2013:38:1958-65.

63 Kowitt S, Sheeran P, Jarman KL, et al. Cigarette constituent health communications for smokers: impact of chemical, imagery, and source. Nicotine Tob Res 2017. doi: 10.1093/ntr/ntx226. [Epub ahead of print 3 Oct 2017].

64 Lakens D. Calculating and reporting effect sizes to facilitate cumulative science: a practical primer for t-tests and ANOVAs. Front Psychol 2013;4:863. 